\title{
Rare Retinal Manifestations in Takayasu Arteritis
}

JAYANTHI PETER, MS, DO, DNB, Assistant Professor; SARADA DAVID, MS, DO, Professor, Department of Ophthalmology; GEORGE JOSEPH, MD, DM, Professor, Department of Cardiology; SABAN HORO, MS, DO, Associate Professor, Department of Ophthalmology; DEBASHISH DANDA, MD, DM, Professor, Department of Clinical Immunology and Rheumatology; JOHN VICTOR PETER, MD, DNB, FRACP, FJFICM, FCICM, FICCM, Associate Professor, Department of Medicine, Christian Medical College Hospital, Ida Scudder Road, Vellore Tamil Nadu 632004, India. Address correspondence to Dr. J.V. Peter; E-mail: peterjohnvictor@yahoo.com.au. J Rheumatol 2013;40:1404-5; doi:10.3899/jrheum.130088

Two patients diagnosed with Takayasu arteritis (TA) using the American College of Rheumatology classification ${ }^{1}$ had uncommon retinal findings. A 54-year-old woman with stable Type I TA for 10 years presented with reduced vision of the right eye for 4 days. Fundus examination showed retinal edema along the inferotemporal arcade (Figure 1) with a corresponding field defect consistent with a diagnosis of branch retinal artery occlusion. The embolic source was probably from the aneurysmally dilated ascending aorta or its branches in this patient with the relatively uncommon aneurysmal form of $\mathrm{TA}^{2}$. The second patient, an 11-year-old girl presenting with 2 months of dyspnea and upper limb claudication and diagnosed as Type V TA was referred for ophthalmic evaluation, 4 days after revascularization of aortic-arch vessels. Fundus showed multiple white-centered hemorrhages bilaterally, sparing the macula, suggestive of Roth spots (Figure 2). Other etiologies of Roth spots ${ }^{3}$ such as sepsis, severe anemia, and infective endocarditis were ruled out. Because ischemic insults to the capillary endothelium can cause retinal hemorrhages ${ }^{3}$, it is not surprising that this patient with carotid occlusion developed Roth spots. However, alternative explanations are plausible. It is recognized that following carotid endarterectomy, neurological complications can be due to either embolic occlusion of distal vessels or cerebral hyperperfusion, with reperfusion injury caused by restoration of flow ${ }^{4}$. Either of these mechanisms following revascularization could have also resulted in Roth spots. Because TA can manifest with retinopathy, iris neovascularization, ocular ischemic syndrome, and anterior ischemic optic neuropathy ${ }^{5}$, periodic ophthalmic assessment is recommended.

\section{REFERENCES}

1. Arend WP, Michel BA, Bloch DA, Hunder GG, Calabrese LH,

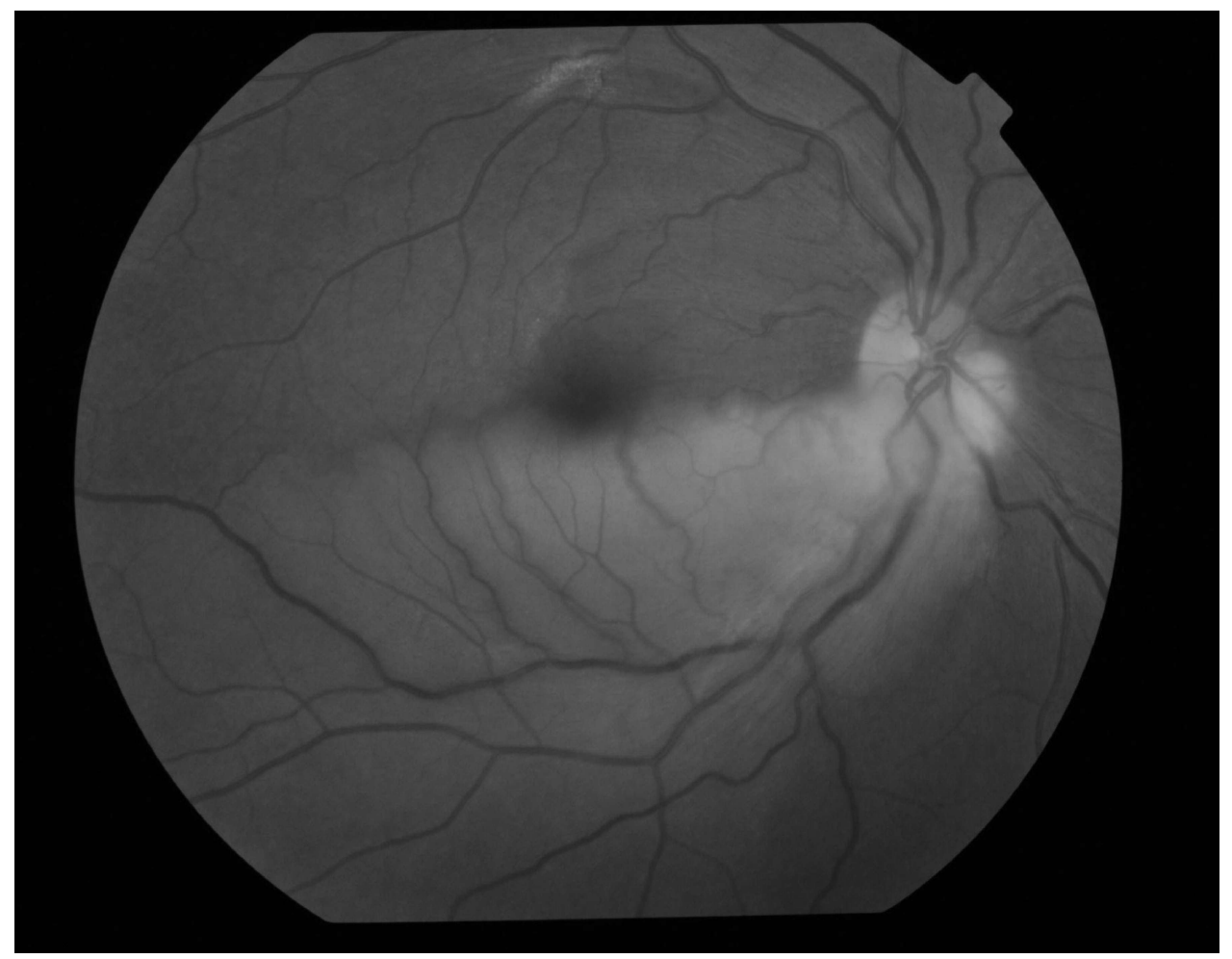

Figure 1. Branch retinal artery occlusion. Fundus photograph showing retinal edema along the infero-temporal arcade of the right eye.

Personal non-commercial use only. The Journal of Rheumatology Copyright @ (2013. All rights reserved. 


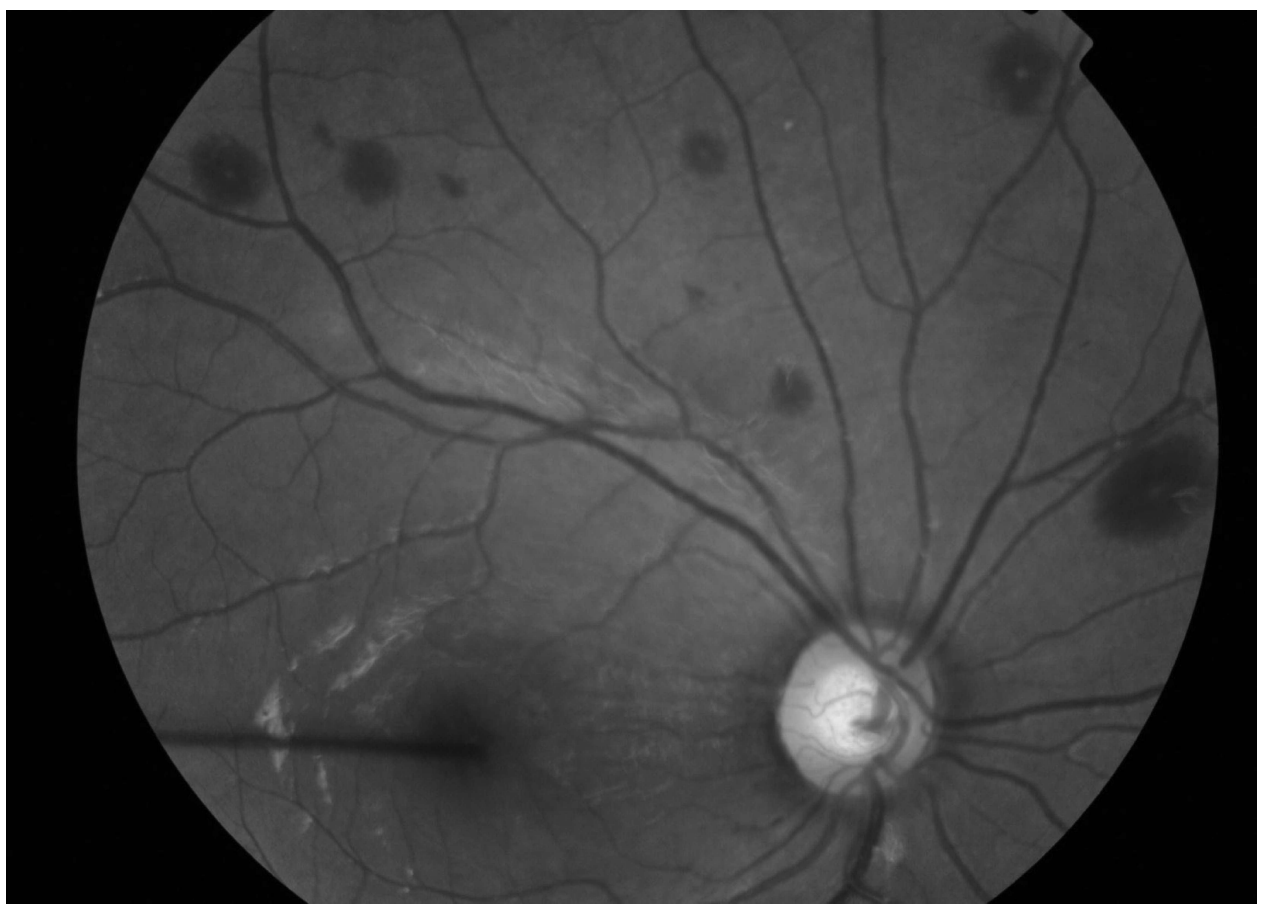

Figure 2. Roth spots. Fundus photograph of the right eye with multiple white-centered hemorrhages all over the fundus bilaterally, sparing the macula.

Edworthy SM, et al. The American College of Rheumatology 1990 criteria for the classification of Takayasu arteritis. Arthritis Rheum 1990;33:1129-34.

2. Kumar S, Subramanyan R, Mandalam KR, Rao VR, Gupta AK, Joseph S, et al. Aneurysmal form of aortoarteritis (Takayasu's disease): Analysis of thirty cases. Clin Radiol 1990;42:342-7.
3. Ling R, James B. White-centred retinal haemorrhages (Roth spots). Postgrad Med J 1998;74:581-2.

4. Adhiyaman V, Alexander S. Cerebral hyperperfusion syndrome following carotid endarterectomy. Q J Med 2007;100:239-44.

5. Peter J, David S, Danda D, Peter JV, Horo S, Joseph G. Ocular manifestations of Takayasu arteritis: A cross-sectional study. Retina 2011;31:1170-8 